\title{
UN GRABADO EXCEPCIONAL DE POSADA
}

\section{Por Manuel González Galván}

José Guadalupe Posada, en su enorme y genial producción de grabados, se ocupó básicamente del hombre vivo y descarnado sobre todo en sus cxtraordinarias muertes-vidas que son las "calaveras". Sus personajes generalmente se mueven en un ámbito vacio, sin marco, ni atmósfera, ni paisaje, si acaso unos rasgos indican el piso en que se apoyan, pero su luz no produce sombras ni define su origen salvo, claro está, en muy raras ocasiones. Ello está bien, ya que a un mundo fantástico como el suyo, corresponde un ambiente fantástico.

El blanco con todas sus posibilidades, fue el mejor fondo escogido para sus personajes y el paisaje natural o urbano no emocionó sus buriles; sus follajes, cuando aparecen, son más bien texturas o calidad de contrastes que observación de la naturaleza; y sus arquitecturas, simples grafias o toques escenográficos para hacernos sentir la calle, su más dilecta referencia al acontecer del pueblo.

Por ello resulta del todo excepcional un grabado en el que supo captar, con toda fidelidad y como tema preponderante, el carácter arquitectónico de un fragmento urbano de la ciudad de Morelia.

Como obsequio llegó a mis manos, ya recortado, el grabado en cuestión, procedente de algún periódico capitalino de fines del siglo pasado; desgraciadamente no ha sido posible identificarlo ni fecharlo por faltar la cabeza de la página en que se publico, pero al reverso lleva impresa una nota firmada por Luis A. Escandón y a la que el grabado sirve para ilustrarla. El objeto de esta nota fue dar a conocer la instalación de luz eléctrica en Morelia, siendo gobernador del Estado de Michoacán el general Mariano Jiménez. De estos escasos datos se deduce la fecha aproximada de 1890 para este acontecimiento, así como para el grabado de referencia.

El general Mariano Jiménez nació en Oaxaca en 1831 y murió en Ia misma ciudad en 1892, luchó en la Guerra de Reforma contra la Intervención Francesa, fue diputado federal varias veces, gobernador interino de Oaxaca y constitucional de Michoacán, a partir de 1885 . Se distinguió por impulsar la cultura y proteger las artes. En Morelia fundó el Museo Michoacano y la Academia de Niñas, apoyó la labor del benemérito y sabio doctor Nicolás León, y bajo sus auspicios se construyeron algunos de los edificios neoclásicos más bellos de Morelia, aś 
como algunos monumentos conmemorativos, entre otros el de Hidalgo, aún existente en el patio del Colegio de San Nicolás. Se preocupó también de la salud y servicios públicos, entre éstos el de la instalación de la luz eléctrica en Morelia, tema de la nota periodistica antes citada y la que transcribimos completa a continuación:

\section{La Luz Eléctrica en Morelia.}

Como si no fueran bastantes a demostrar las progresistas ideas del señor General Mariano Jiménez, Gobernador de Michoacán, todas las obras materiales de ornato que ha emprendido y llevado a buen fin, quiso una vez más, realizar otra, que por su interés no podía quedar en proyecto, aun cuando para conseguirlo, habrian de hacerse sacrificios.

Nada hay que arredre al señor Jiménez cuando se trata de una mejora que redunde en beneficio público y a la mayor brevedad hizo que se ins. talara en Morelia la luz eléctrica.

La casa de los Sres. Adam sucesores, establecida en esta capital en la "Calle del 5 de Mayo" núm. 4, fue la encargada de llevar a efecto la importante obra. Quedó establecido motor y dinamos en el ex-convento de Teresas en un vasto y elegante salón.

La maquinaria es de lo más supremo que se conoce siendo el motor de fuerza de ciento veinticinco caballos; tres dinamos de treinta lámparas que produce cada una de ellas, luz equivalente a dos mil bujlas.

Cada dinamo tiene su circuito especial y se puede cambiar.

El resultado es magnífico, tanto más, cuanto que, en las torres de la catedral se establecieron diez y seis arcos que iluminan a distancia de tres. millas, poco más o menos. La luz es clara y brillante y sin duda alguna, la mejor que en el pais existe.

Satisfecho debe estar el Sr. General Jiménez por tan importantísima mejora que implantó en la ciudad de Morelia, como agradecidos se muestran todas las clases sociales por ésta y las muchas pruebas que el ilustre oaxaqueño ha dado a su tierra adoptiva, Michoacán, por embellecerle y llevarlo por la via del progreso.

La casa de Adam, sucesores, merece también elogios, no sólo por haber cumplido fielmente con sus compromisos hasta la fecha, sino también porque ha probado que mucho entienden en la materia y que las maquinarias difícilmente pueden tener rival en Estados Unidos de donde fueron im. portadas.

Con gobernantes como el Sr. General Jiménez y contratista como los Sres. Adam sucesores, México, en general, mucho avanzará.

Luis A. Escandón.

Por lo anterior comprobamos que nuestra visión e ilusión del "progreso" es anticuada, ya que sigue siendo la misma que se tenía hace ochenta años, pues como se observará sólo se toma en cuenta y se men- 
DOI: http://dx.doi.org/10.22201/iie.18703062e.1971.40.933

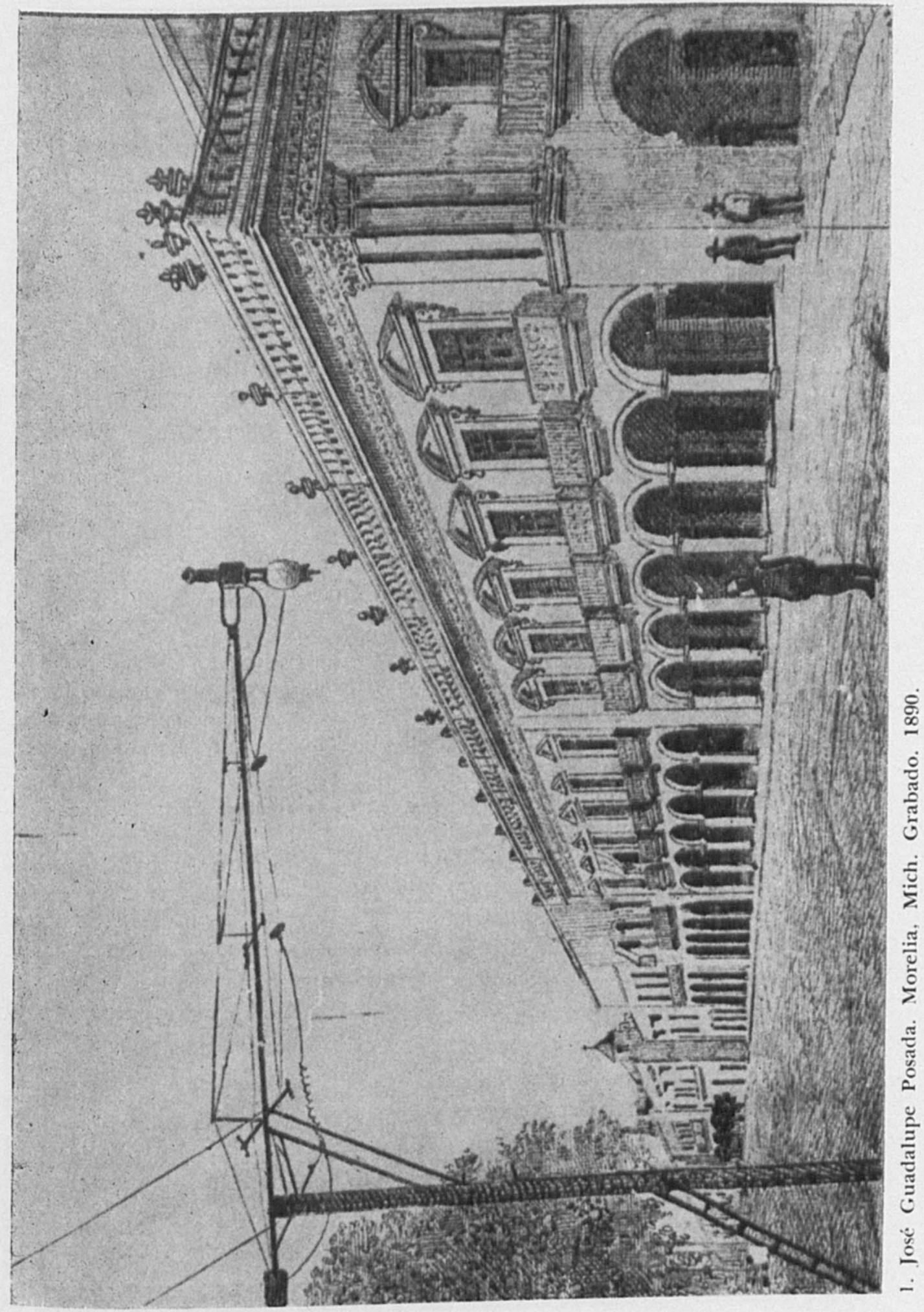


DOI: http://dx.doi.org/10.22201/iie.18703062e.1971.40.933

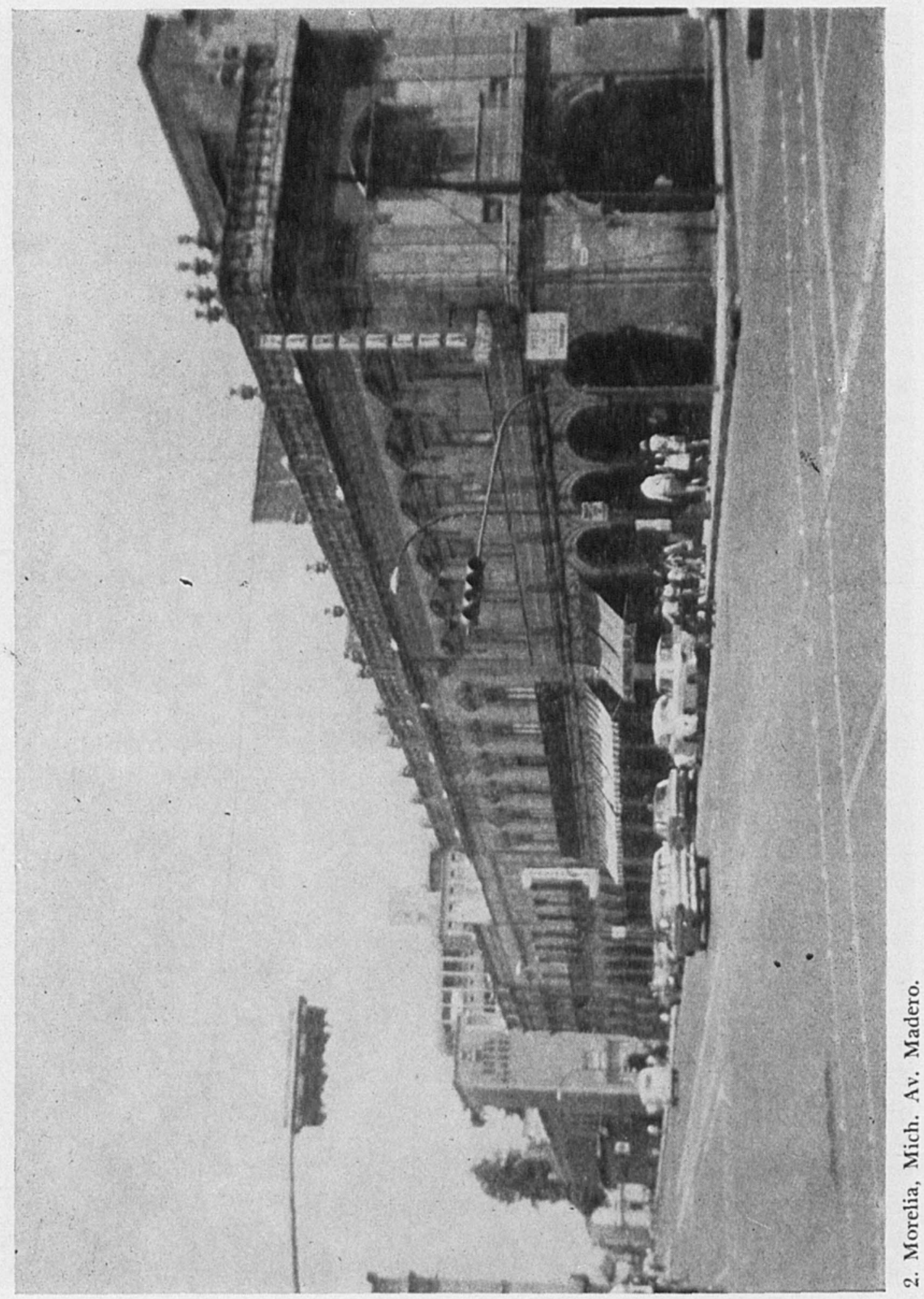


ciona lo práctico, lo útil y lo económico, pero no así lo estético que se rclega a segundo plano, o ni siquiera se toma en cuenta, como se ve comparando las dos ilustraciones: el grabado del siglo XIx y la fotografia del xx. Lo necesario, al romper el estricto límite de lo discreto y prudente cae en el exceso de la superfluidad antiestética, tal es el caso de los fésimos postes que debieron colocarse para instalar la luz eléctrica y que tan claro ilustra el grabado de Posada. Actualmente, aunque esos postes ya no existan, sus descendientes se han multiplicado y hoy ahogan la ciudad con modernos "arbotantes", antenas de televisión, alambres, y los recién instalados semáforos "de látigo" que, como hace un siglo, por un lado dan un servicio pero por el otro insultan la belleza urbana de la población por carecer, todavia, de un criterio equilibrado en su diseño y colocación.

Ahora bien, y volviendo al grabado de Posada, éste mide $20.8 \times 15$ $\mathrm{cm}$., está firmado en el ángulo inferior derecho y representa el tramo de portal que corre al costado norte de la plaza mayor de Morelia, llamada "De Los Mártires" por haber sido ejecutados en ella numerosos. héroes de las distintas etapas de nuestra evolución social. Arquitectónicamente este trozo urbano se ha conservado casi intacto desde el siglo anterior hasta nuestros dias; sólo ha desaparecido la esquina del extremo poniente, hoy sustituida por un buen edificio de principios de siglo, de arquitectura ecléctica no exenta de belleza y que, sobre todo, no rompe, ni en materiales ni en proporciones, la unidad del conjunto; lo que no sucede con la esquina que le sigue, donde existió un edificio colonial destruido por un incendio y en su lugar hoy se levanta el Hotel Alameda, el que sí altera la volumetría y el orden espacial de la plaza, pues excede en altura y número de pisos a todos los edificios restantes y su estilo moderno rompe la unidad de conjunto. Por lo demás, básicamente la perspectiva es la misma que grabara Posada allá por 1890, cuando estaba en su plenitud creativa, pues aún tenía pocos años en la ciudad de México a la que llegó en 1887, de 36 años de edad. Éste es, pues, uno de sus grabados anteriores a sus célebres calaveras. La ilustración es a tal grado fiel con la realidad que nos hace suponer que, habiendo sido realizada por encargo, el artista no hizo el viaje especial a Morelia para ejecutarla y, posiblemente, se basó en una fotografía, lo que es por demás legítimo y aun prueba de fuerza creadora cuando. la hay, pues lo mismo da transformar para el arte, basándose en la observación directa que en la indirecta realidad plástica, aunque inerte como puede ser una fotografia. Esto sucede cuando la personalidad del 
artista supera o se impone a la copia, lo que es frecuente en quien interpreta el paisaje urbano, como es el caso, para citar uno solo, del pintor Maurice Utrillo, que se ayudaba de postales y fotografías para plasmar sus visiones subjetivas de calles e iglesias de Paris y otras ciudades francesas.

En el caso del grabado que comentamos no sólo se identifica el conjunto, sino cada uno de sus elementos, pero todo está matizado por la inconfundible trama que forma el rasgueo del dibujo de Posada al hacer las incisiones sobre la plancha metálica. Alli está, disciplinada por la perspectiva, su manera de perfilar las formas, de producir las sombras y, sobre todo, sus figuras humanas, que son necesarias para dar escala $y$ marcar los planos en profundidad, sin embargo, apenas aparecen en número de cuatro, $y$, así, la dilatada fuga de la perspectiva deja sentir una soledad en donde la presencia arquitectónica es la que verdaderamente puebla la lámina en ausencia del hombre.

Posada, que tan maravillosamente supo hacer vivir y hablar a las osamentas, aun con la ausencia de la fugacidad de la piel, captó en este grabado lo más permanente de una ciudad, la estructura interna de su vida cotidiana, constituida por su arquitectura. Así Posada, que vela a través de lo accidental, supo captar la "calavera" intemporal de un fragmento urbano, en este grabado tan suyo, como excepcional en el conjunto de su obra. 